\title{
DEPÓSITOS MINERAIS ANTROPOGÊNICOS: UMA SÍNTESE PRELIMINAR DOS TRABALHOS DE PESQUISA MINERAL NOS REJEITOS DAS MINAS CAFUCA, BODÓ/RN E BARRA VERDE, CURRAIS NOVOS/RN
}

\section{Mário Tavares de Oliveira Cavalcanti Neto}

Geólogo, Especialização em Metalogênese do Pré-Cambriano e suas Mineralizações, Especialização senso latu em Geologia Ambiental, Mestrado em Eng. de Produção, Líder do Grupo de Pesquisa Mineral do IFRN. e-mail: mario@cefetrn.br

\section{José Vilanir de Sousa Brito}

Minerador, com experiência na lavra de tailings de scheelita das minas Barra Verde e Cafuca, membro supervisor do Grupo de Pesquisa Mineral

e-mail: vilanirbrito@bol.com.br

\section{RESUMO}

Nesse trabalho são definidos os depósitos minerais antropogênicos, com base nos resultados preliminares dos trabalhos de Pesquisa Mineral nos rejeitos das minas Cafuca e Barra Verde, tradicionais minas de scheelita do Estado do Rio Grande do Norte.

PALAVRAS-CHAVE: Scheelita, Tailing, Depósitos Minerais Antropogênicos, Mina Cafuca, Mina Barra Verde

\section{ANTHROPOGENIC ORE DEPOSITS: A PRELIMINARY SUMMARY OF THE MINERAL EXPLORATION WORKS OF THE CAFUCA MINE, BODÓ/RN AND BARRA VERDE MINE, CURRAIS NOVOS/RN.}

\section{ABSTRACT}

In this paper are defined anthropogenic ore deposits, based on preliminary results of Mineral Exploration in the tailings of Cafuca and Barra Verde mines, traditional scheelite mines of the Rio Grande do Norte State.

KEY-WORDS: Scheelite, Tailing, Antropogenic Ore Deposit, Cafuca Mine, Barra Verde Mine. 


\section{DEPÓSITOS MINERAIS ANTROPOGÊNICOS: UMA SÍNTESE PRELIMINAR DOS TRABALHOS DE PESQUISA MINERAL NOS REJEITOS DAS MINAS CAFUCA, BODÓ/RN E BARRA VERDE, CURRAIS NOVOS/RN}

\section{INTRODUÇÃO}

Os rejeitos produzidos pela atividade de mineração contêm teores anômalos da substância mineral útil e, por isto, podem se constituírem em Depósitos Minerais, do tipo Antropogênico, ensejando uma oportunidade de geração de atividade econômica produtiva.

Por se tratar de material já desmontado, com volume à vista e teor médio facilmente obtido através de trabalhos de pesquisa e prospecção mineral, esses depósitos ensejam baixo risco de pay-back, embora demandem alta tecnologia de processamento necessária para a recuperação de finos em escala industrial (Carvalho et. al. 2002, Silva Jr et. al. 2008).

No semi-árido nordestino o estudo desses depósitos ganha em importância econômica e social, pois abre a possibilidade de geração de emprego e renda numa região de poucas oportunidades. Este texto enfoca exclusivamente as questões relacionadas à Prospecção e Pesquisa Mineral e exemplifica com os trabalhos realizados nas Minas de scheelita Cafuca e Barra Verde.

Estudos recentes mostram que regulagens nos equipamentos em operação associados a otimização de lay-out elevam a recuperação de processo em escala de laboratório (Leite et. al. 2007).

\section{O AMBIENTE ANTROPOGÊNICO COMO UM PROCESSO FORMADOR DE DEPÓSITO MINERAL}

Os Depósitos Minerais Antropogênicos podem ser englobados em dois tipos genéricos: (i) os rejeitos da lavra, também conhecidos como rejeito de "run-of-mine” ou Bota-fora e (ii) os rejeitos do beneficiamento ou tratamento mineral, também chamados de Tailing. Os primeiros são constituídos, predominantemente, de blocos desde métricos à sub-milimétricos provenientes do desmonte de rochas contendo minério e encaixantes (no caso das minas em epígrafe predominam calciossilicáticas, gnaisses e mármores). O segundo tipo é proveniente das diversas etapas do processamento mineral ou de etapas específicas (rejeito de mesa, rejeito de eletro-imã, rejeito de jig etc...) dependendo da disposição dos mesmos pela empresa de mineração e/ou garimpeiros que o produziu. O prospector deve mapeá-los como unidades litológicas antropogênicas individualizadas e reportar-se ao teor de cada uma, como o faz nos depósitos naturais secundários e primários. Um conhecimento das características do rejeito de cada uma dessas etapas de processamento é fundamental para o mapeamento adequado dessas unidades.

As características Gerais dos Depósitos Antropogênicos, podem ser resumidas conforme abaixo:

a) Baixa relação minério:estéril e concentrações preferencialmente nas frações granulométricas mais finas no caso do Tailing; 
b) Nos Tailings o teor recuperável é, via de regra, significativamente menor que o teor médio do Depósito Mineral, devido às dificuldades de recuperação de frações granulométricas mais finas em escala industrial. Este fato demanda estudos de caracterização tecnológica para o seu processamento adequado;

c) Da mesma forma que no ambiente natural secundário, nos Depósitos Minerais Antropogênicos o teor de metal tende a uma homogeneização. Assim, o Coeficiente de Variação Estatístico tende a ser menor quando comparado ao do depósito primário;

d) Os custos e tempo desprendidos pelos trabalhos de prospecção e pesquisa mineral, visando à cubagem do metal contido, são muito mais baixo quando comparados aos depósitos primários;

e) Geralmente são acumulações ao ar livre que impactam negativamente no cenário natural paisagístico (SEDEC 2006, Pfeifer, 1999). O processo extrativo desses depósitos ensejaria medida de recuperação ou mitigação deste impacto.

Dependendo do tempo de exposição às intempéries, os processos naturais superimpostos podem ter maior ou menor contribuição no aumento da concentração da substância útil quer seja em toda área do Tailing ou em porções onde a ação intempérica é mais acentuada ou capaz de promover a concentração natural do mineral-minério. No Tailing da mina Barra Verde dois processos superimpostos foram identificados: a erosão eólica transportando os minerais mais leves, a semelhança de placers eólicos em marcas de ondas, e as águas meteóricas carreando os materiais mais pesados para a base das pilhas de rejeito. O primeiro tipo de superposição é mais importante, ocasionando concentrações localizadas de scheelita próximo à superfície. Esse aspecto ganha em importância na questão da representatividade da amostragem. Porém não tem importância na formação de Depósito Mineral.

\section{OS REJEITOS DA MINA CAFUCA}

Foi realizado um mapeamento de todas as unidades litológicas naturais e antropogênicas, sendo reconhecidos Tailings e Bota-Fora.

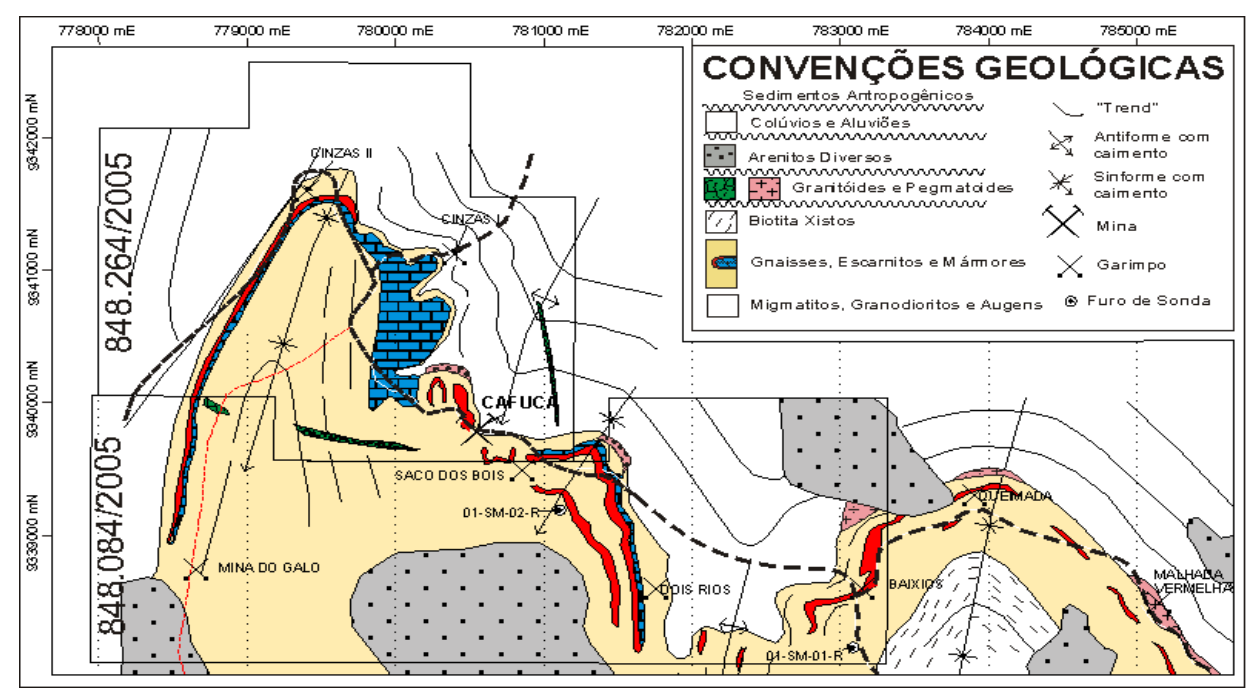

Figura 1: Mapa geológico da Faixa Cafuca - Malhada Vemelha (parcialmente compilado de Nesi et. all, 1981) 
Nos Tailing foram realizadas amostragens através de 29 furos com trado manual eventualmente auxiliado por abertura de poços de até 2,0 $\mathrm{m}$ de profundidade com retro escavadeira naquelas locais de maior volume.

\section{TABELA 1: RESUMO DOS RESULTADOS OBTIDOS NO TAILING DA MINA CAFUCA}

\begin{tabular}{|c|c|c|c|c|c|c|c|c|c|c|}
\hline & & & & & VOI & UME (1) & & TEOF & $2 \% \mathrm{~V}$ & $\left.\mathbf{O}_{3}\right) *$ \\
\hline FURO & UTM_E & UTM_N & $\begin{array}{c}\text { PROF. } \\
\text { (m) }\end{array}$ & $\begin{array}{c}\text { PESO } \\
\text { (Kg) }\end{array}$ & $>1 \mathrm{~mm}$ & $\begin{array}{l}1 \mathrm{~mm}- \\
0,1 \mathrm{~mm}\end{array}$ & $\begin{array}{l}<\mathbf{0 , 1} \\
\mathbf{m m}\end{array}$ & $\begin{array}{l}>1 \\
\text { mm }\end{array}$ & $\begin{array}{c}1 \mathrm{~mm} \\
-0,1 \\
\mathrm{~mm} \\
\end{array}$ & $\begin{array}{c}<\mathbf{0 , 1} \\
\mathbf{m m}\end{array}$ \\
\hline FC-01 & 780.397 & 9.339 .941 & 4,55 & 2,00 & 0,36 & 1,48 & 0,16 & 0,15 & 0,50 & 1,25 \\
\hline FC-02 & 780.429 & 9.339 .944 & 3,90 & 1,72 & 0,31 & 1,27 & 0,14 & 0,28 & 0,38 & 2,02 \\
\hline FC-03 & 780.407 & 9.339 .967 & 3,60 & 1,58 & 0,28 & 1,17 & 0,13 & 0,25 & 0,42 & 1,00 \\
\hline FC-04 & 780.386 & 9.339 .989 & 3,55 & 1,56 & 0,28 & 1,16 & 0,12 & 0,25 & 0,34 & 0,95 \\
\hline FC-05 & 780.477 & 9.339 .953 & 2,75 & 1,21 & 0,21 & 0,90 & 0,10 & 0,18 & 0,28 & 0,65 \\
\hline FC-06 & 780.454 & 9.339 .969 & 1,55 & 0,68 & 0,12 & 0,50 & 0,06 & 0,15 & 0,38 & 1,85 \\
\hline FC-07 & 780.431 & 9.339 .988 & 2,55 & 1,12 & 0,20 & 0,83 & 0,09 & 0,25 & 0,42 & 1,00 \\
\hline FC-08 & 780.410 & 9.340 .004 & 3,15 & 1,39 & 0,25 & 1,03 & 0,11 & 0,30 & 0,30 & 1,00 \\
\hline FC-09 & 780.397 & 9.340 .023 & 2,40 & 1,06 & 0,19 & 0,78 & 0,09 & 0,35 & 0,30 & 1,00 \\
\hline FC-10 & 780.413 & 9.340 .054 & 1,15 & 0,51 & 0,09 & 0,37 & 0,04 & 0,40 & 0,30 & 0,80 \\
\hline FC-11 & 780.428 & 9.340 .037 & 2,20 & 0,97 & 0,17 & 0,72 & 0,08 & 0,30 & 0,38 & 1,05 \\
\hline FC-12 & 780.443 & 9.340 .022 & 3,50 & 1,54 & 0,27 & 1,14 & 0,13 & 0,30 & 0,44 & 1,10 \\
\hline FC-13 & 780.466 & 9.340 .006 & 2,65 & 1,17 & 0,21 & 0,86 & 0,10 & 0,15 & 0,30 & 0,68 \\
\hline FC-14 & 780.493 & 9.339 .991 & 1,70 & 0,75 & 0,13 & 0,55 & 0,06 & 0,15 & 0,30 & 0,72 \\
\hline FC-15 & 780.505 & 9.340 .017 & 1,00 & 0,44 & 0,08 & 0,32 & 0,04 & 0,35 & 0,30 & 0,84 \\
\hline FC-16 & 780.483 & 9.340 .030 & 1,55 & 0,68 & 0,12 & 0,50 & 0,06 & 0,30 & 0,55 & 0,95 \\
\hline FC-17 & 780.462 & 9.340 .044 & 2,05 & 0,90 & 0,16 & 0,67 & 0,07 & 0,18 & 0,60 & 0,78 \\
\hline FC-18 & 780.445 & 9.340 .058 & 1,50 & 0,66 & 0,12 & 0,49 & 0,05 & 0,15 & 0,83 & 0,83 \\
\hline FC-19 & 780.429 & 9.340 .072 & 1,10 & 0,48 & 0,09 & 0,35 & 0,04 & 0,22 & 0,45 & 1,12 \\
\hline FC-20 & 780.511 & 9.340 .050 & 1,25 & 0,55 & 0,10 & 0,41 & 0,04 & 0,20 & 0,22 & 1,24 \\
\hline FC-21 & 780.498 & 9.340 .057 & 1,80 & 0,79 & 0,14 & 0,59 & 0,06 & 0,14 & 0,27 & 1,55 \\
\hline FC-22 & 780.481 & 9.340 .070 & 1,95 & 0,86 & 0,15 & 0,63 & 0,07 & 0,16 & 0,28 & 1,47 \\
\hline FC-23 & 780.462 & 9.340 .081 & 1,35 & 0,59 & 0,11 & 0,43 & 0,05 & 0,15 & 0,34 & 0,80 \\
\hline FC-24 & 780.447 & 9.340 .092 & 1,05 & 0,46 & 0,08 & 0,34 & 0,04 & 0,15 & 0,41 & 0,76 \\
\hline FC-25 & 780.503 & 9.340 .088 & 1,15 & 0,51 & 0,09 & 0,37 & 0,04 & 0,22 & 0,45 & 0,64 \\
\hline FC-26 & 780.484 & 9.340 .094 & 1,00 & 0,44 & 0,08 & 0,32 & 0,04 & 0,18 & 0,35 & 1,10 \\
\hline FC-27 & 780.465 & 9.340 .103 & 0,95 & 0,42 & 0,07 & 0,31 & 0,03 & 0,12 & 0,36 & 0,90 \\
\hline FC-28 & 780.481 & 9.340 .111 & 0,60 & 0,26 & 0,04 & 0,20 & 0,02 & 0,10 & 0,28 & 1,24 \\
\hline FC-29 & 780.498 & 9.340 .109 & 0,45 & 0,20 & 0,04 & 0,14 & 0,02 & 0,30 & 0,30 & 0,73 \\
\hline MÉDIAS & & & & & & & & $0,22 \%$ & $0,38 \%$ & $1,035 \%$ \\
\hline
\end{tabular}


Todo o material coletado em cada furo manual foi pesado e, após o peneiramento, foi pesada cada uma das três frações granulométricas, a saber: maior que $1 \mathrm{~mm}$, entre $1 \mathrm{~mm}$ e 0,1 mm e abaixo de 0,1 mm. Em seguida as amostras foram quarteadas e uma alíquota foi submetida à análise de teor.

\section{TABELA 2: RESULTADO DE VOLUME E TEOR DAS AMOSTRAS DE TAILING DA MINA CAFUCA (MÉDIA PONDERADA AO VOLUME DAS FAIXAS GRANULOMÉTRICAS)}

\begin{tabular}{|c|c|c|c|}
\hline & $\mathbf{+ 1} \mathbf{m m}$ & $\mathbf{1 . 0} \mathbf{- 0 . 1} \mathbf{~ m m}$ & $\mathbf{- 0 . 1} \mathbf{~ m m}$ \\
\hline VOLUME (\%) & 16 & 74 & 10 \\
\hline TEOR MÉDIO $\left(\% \mathrm{WO}_{3}\right)$ & 0,17 & 0,25 & 1,18 \\
\hline
\end{tabular}

O Tailing é composto predominantemente por material na faixa granulométrica entre 1,0 $\mathrm{mm}$ e $0,1 \mathrm{~mm}$ e o teor médio ponderado ao volume é de $0,13 \% \mathrm{WO}_{3}$. Conclui-se também que existe uma tendência de aumento de teor de trióxido de tungstênio nas frações mais finas.

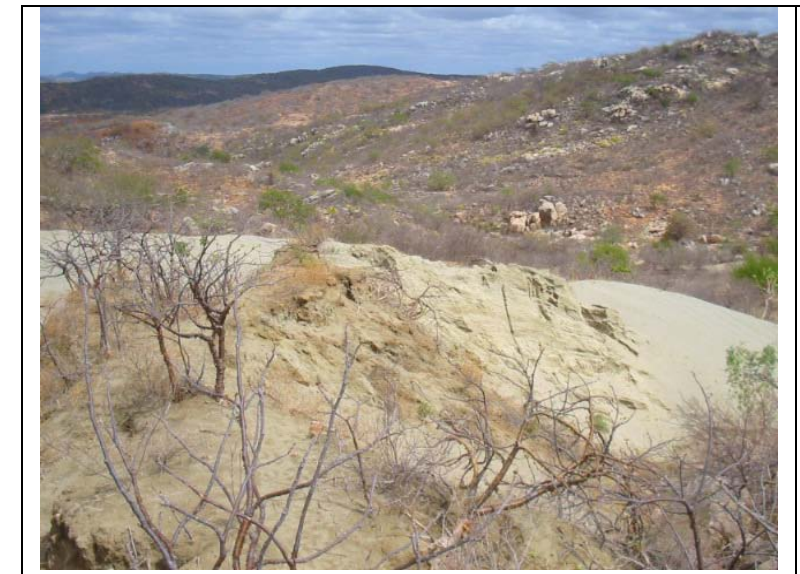

(a)

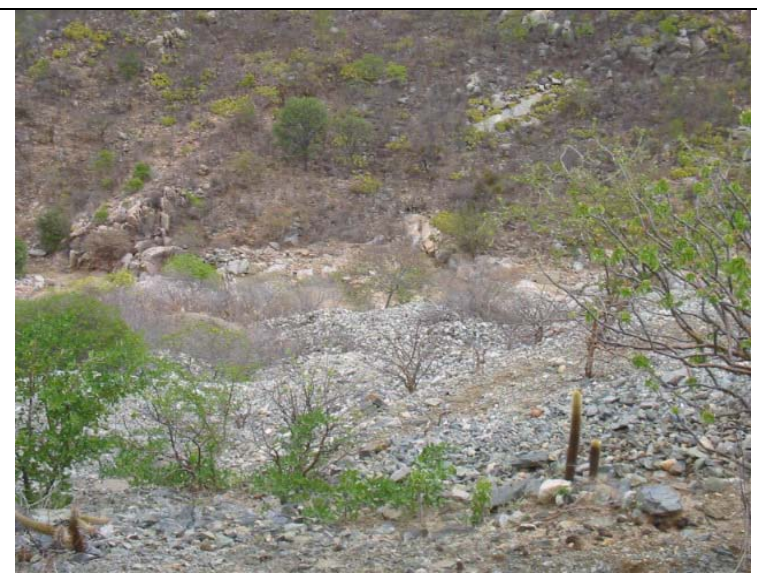

(b)

Figura 2: Foto dos Depósitos Minerais Antropogênicos da Mina Cafuca. (a) Tailing ou Rejeito do Processamento Mineral; (b) Rejeito da Lavra ou de Run of Mine ou simplesmente "Bota-Fora".

Considerou-se ainda a possibilidade de aumentar o teor de alimentação, descartando o material com faixa granulométrica acima de $1,0 \mathrm{~mm}$. Nesse caso o teor médio ponderado passa a ser de $0,18 \%$ de $\mathrm{WO}_{3}$ com perda de cerca de $16 \%$ de material e, conseqüentemente, da Vida Útil, correspondente ao descarte da faixa granulométrica maior que $1 \mathrm{~mm}$ que seria rejeitada no processo de peneiramento. Assim, seria processado apenas os materiais correspondentes às faixas granulométricas entre $1,0 \mathrm{~mm}$ e $0,1 \mathrm{~mm}$ e abaixo de 0,1 mm. Não foi considerada a possibilidade de descarte da menor fração granulométrica analisada tendo em vista a impossibilidade de se excluir, por peneiramento em um processo em escala industrial, material abaixo de $0,1 \mathrm{~mm}$.

Para a verificação dessa possibilidade foram instalados 1 Grupo Gerador e rede elétrica, adução e distribuição de água a partir do açude de Cafuca, 1 peneira com malha de $1 \mathrm{~mm}, 1$ moinho de martelo, 1 Jig panamericano e uma mesa vibratória. Foi mobilizado ainda 1 retroescavadeira, uma pá carregadeira, 1 Caminhão Basculante para carregamento e transporte do tailing até a planta piloto, além de material de reposição e consumo. 


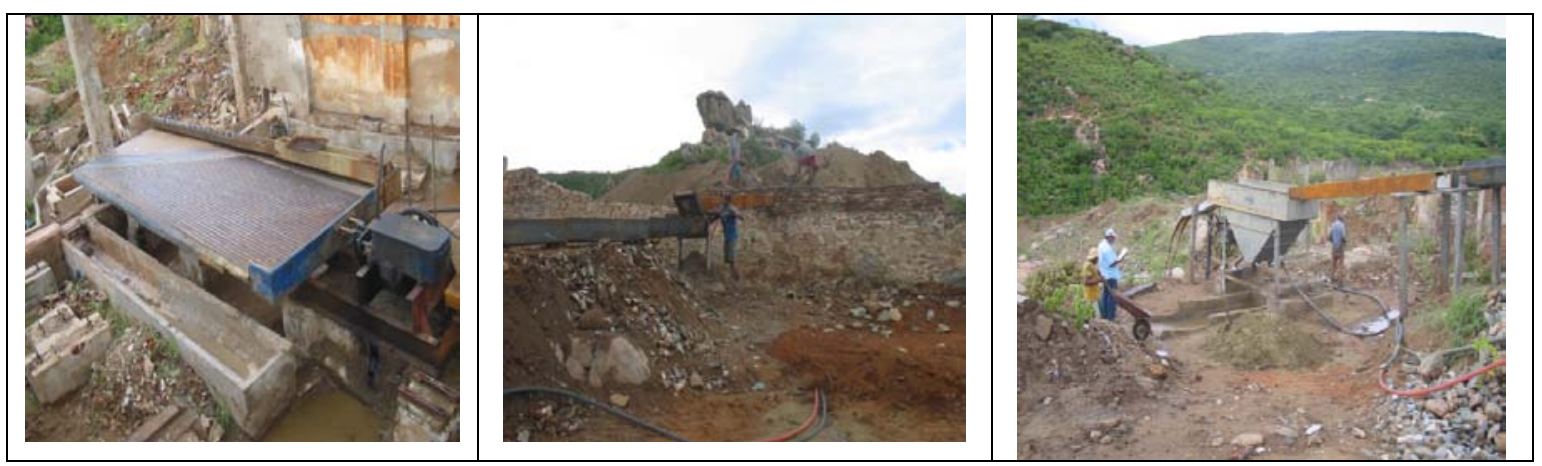

F/igura 3: Instalação de Mesa, Jig para testes com o Tailing da Mina Cafuca.

Os ensaios exploratórios usando aqueles equipamentos descritos e regulagens tradicionais apresentam uma recuperação de $40 \%$ e concentrados de scheelita com teor de $50 \%$ de $\mathrm{WO}_{3}$. Em termos econômicos observou-se que os custos de produção foram bastante elevados devido ao uso do óleo diesel para acionar o grupo gerador e outras máquinas.

$\mathrm{O}$ teor de corte situou-se em torno de $0,30 \%$ de $\mathrm{WO}_{3}$. Estima-se que o uso de energia elétrica reduziria esse teor de corte para $0,12 \%$ de $\mathrm{WO}_{3}$.

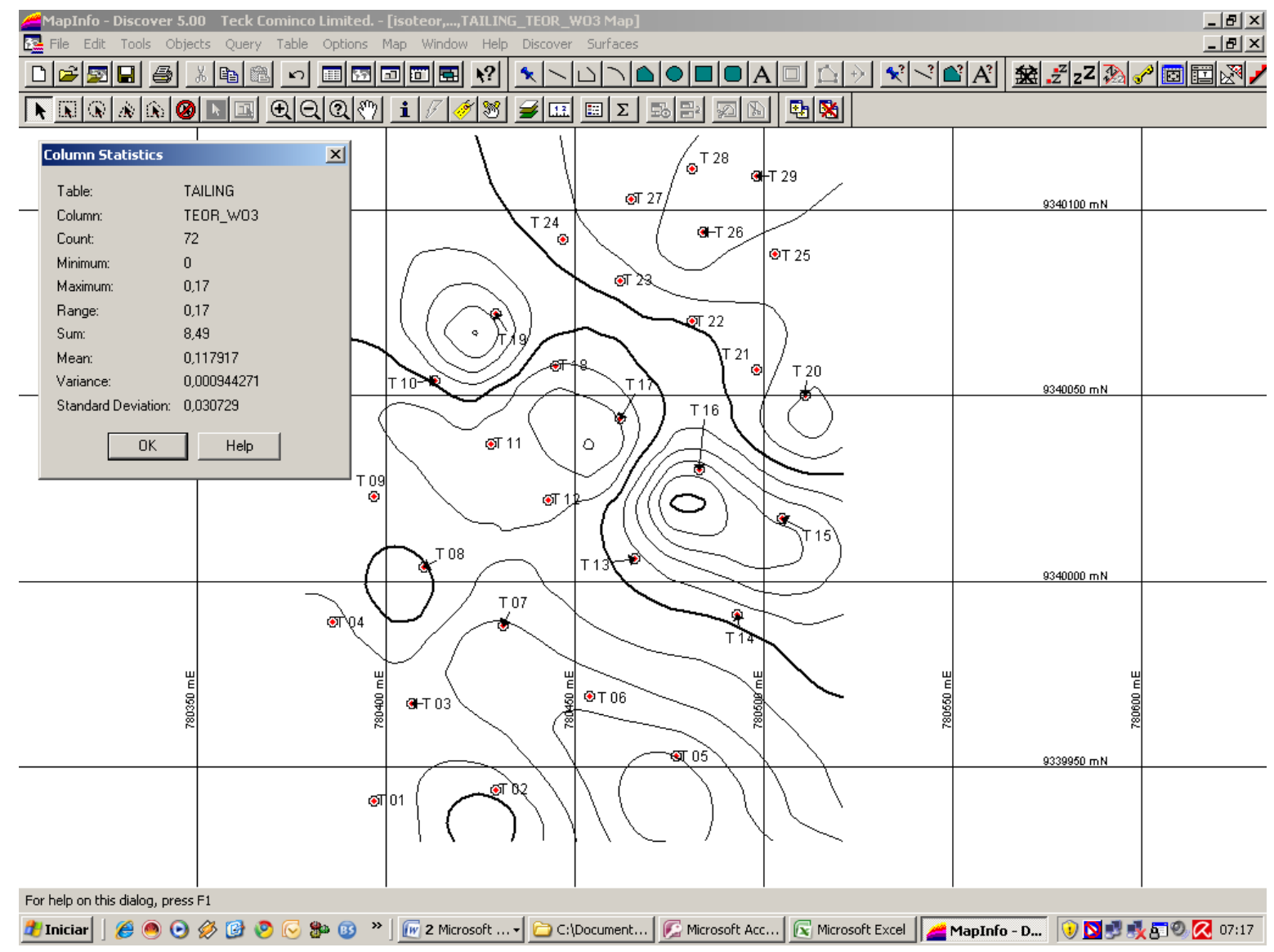

Figura 4: Mapa de Locação dos Furos de Sonda, Isoteores e principais resultados estatísticos. (O software MapInfo versão 7.5 apresenta a média aritmética). 
A área do Tailing foi calculada em $19.270 \mathrm{~m}^{2}$ a partir de uma ferramenta do software MapInfo, versão 7.5. A profundidade média foi de 2,0 m, obtida a partir de 29 furos a trado manual. A densidade do Tailing é de $1,8 \mathrm{ton} / \mathrm{m}^{3}$, e a quantidade de $\mathrm{WO}_{3}$ contido é de 93,40 toneladas.

\section{TABELA 3: SÍNTESE DAS RESERVAS DO Tailing DA MINA CAFUCA}

\begin{tabular}{|l|c|c|c|}
\hline \multicolumn{1}{|c|}{ TAILING } & $\mathbf{+ 1 m m}$ & $\mathbf{1 , 0} \mathbf{~ m m ~ - ~ 0 , 1 ~} \mathbf{~ m m}$ & $\mathbf{- 0 , 1} \mathbf{~ m m}$ \\
\hline $\mathrm{WO}_{3}$ CONTIDO POR GRAN. (ton) & 16,67 & 69,12 & 7,61 \\
\hline TOTAL DE $\mathrm{WO}_{3}$ CONTIDO (ton) & \multicolumn{3}{|c|}{ GRAN = granulometria ou faixa granulométrica } \\
\hline
\end{tabular}

Considerando o preço do $\mathrm{Kg}$ de trióxido de tungstênio a R\$ 20,00 temos que o valor econômico do Tailing é de R \$ 1.868.091,00 (Hum milhão, Oitocentos e Sessenta e Oito mil e Noventa e Hum Reais), sem considerar as perdas do processamento.

\section{MINA BARRA VERDE}

\section{1 - Introdução}

Na mina Barra Verde foram reconhecidos os "Sedimentos Antropogênicos" denominados de Tailing e "Bota-Foras", mineralizados em scheelita e molibdênio, ambos resultados de aproximadamente 50 (cinqüenta) anos de atividades de mineração (ver figura 5).
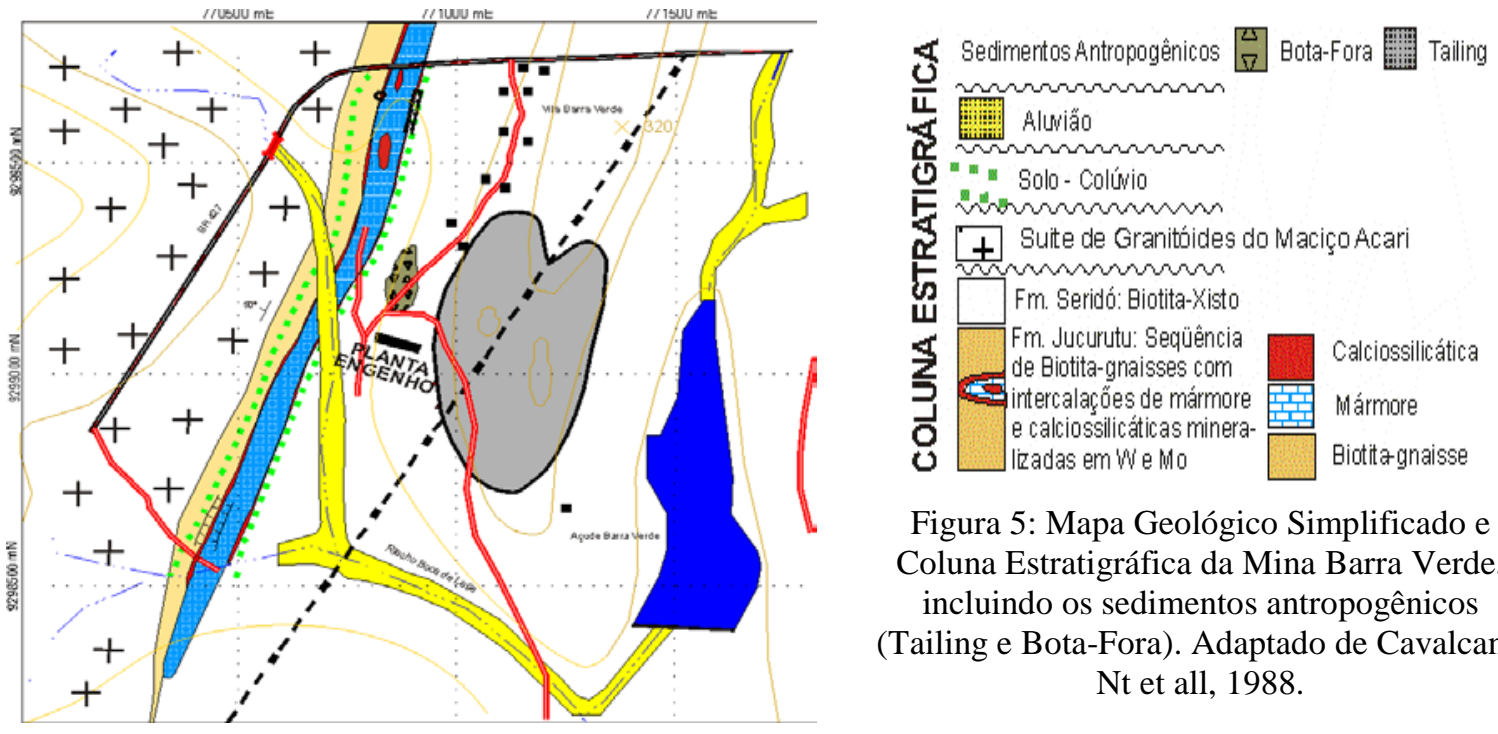

Figura 5: Mapa Geológico Simplificado e Coluna Estratigráfica da Mina Barra Verde, incluindo os sedimentos antropogênicos (Tailing e Bota-Fora). Adaptado de Cavalcanti Nt et all, 1988.

\section{2 - Os Tailings}

Os Tailings foram depositados no entorno da planta de processamento mineral desde 1942 até início da década de 80, quando as minas tradicionais deixaram de operar. São sedimentos inconsolidados de granulometria variando desde areia fina a média até silte-argilosa, coloração esbranquiçada, amarelada, creme e acinzentada. Geograficamente se distingue 
uma porção amarelada escura oriunda dos processos de ustulação e separação eletromagnética (rejeito de separação magnética).

Aqueles Tailing de granulometria de cor acinzentada correspondem ao rejeito mais antigo processado por volta das décadas de 40 e 50, logo no início da mineração de scheelita em Currais Novos. Coincidem também com os Tailing mais ricos em $\mathrm{WO}_{3}$. Aqueles de coloração amarelada e esbranquiçada correspondem à maior porção mapeada e ao material produzido nas décadas de 60,70 e 80 , sendo comparativamente mais pobres em $\mathrm{WO}_{3}$. Formam "morrotes" artificiais, semelhantes às dunas de areia, com padrão aerofotogramétrico distinto das encaixantes, textura fotográfica fina, coloração branca. São observáveis também em imagens de radar e satélite (ver figura 6).

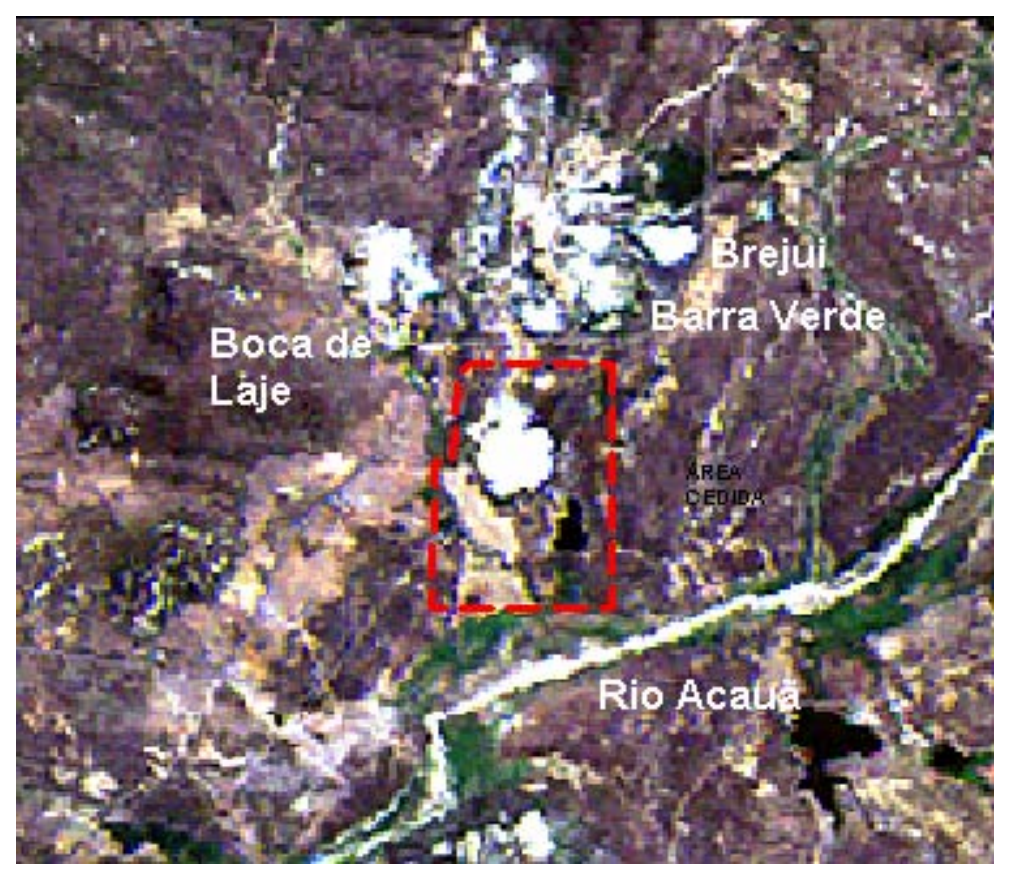

Figura 6: Imagem de Satélite (Google Earth) da região das minas Brejui, Barra Verde e Boca de Laje evidenciando os Tailings de cada mina e a área enfocada neste artigo (destacada em tracejado de cor vermelha).

Os Tailings das minas de scheelita de Currais Novos ocupam áreas relativamente extensas, com formatos elípticos à semi-circulares, alcançando até $700 \mathrm{~m}$ (setecentos metros - rejeito da Brejui e Barra Verde por ex) de comprimento, medidos ao longo do eixo maior da elipse, conforme ilustra a figura 6 . Alcançam até $20 \mathrm{~m}$ (vinte metros) de altura, nos seus pontos mais altos (ver figura 7). 


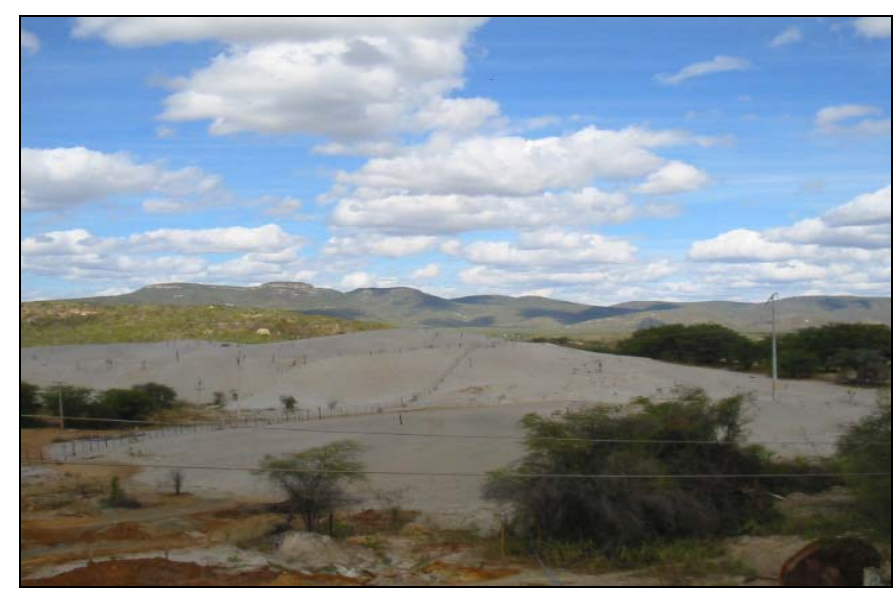

Figura 7: Foto do Tailing, unidade estratigráfica correlata aos sedimentos antropogênicos mapeados na mina

\section{3 - Metodologia}

Barra Verde.

Os trabalhos realizados nos Tailings constaram do mapeamento planimétrico do seu contorno com GPS de bolso tipo GARMIN 60 Csx através de caminhamentos contornando o corpo hospedeiro e leitura de coordenadas a cada $50 \mathrm{~m}$ a $100 \mathrm{~m}$.

Foram realizadas 72 (Setenta e Duas) sondagens a trado manual nos Tailings da mina Barra Verde. O furo mais profundo atingiu 4,10 $\mathrm{m}$ e o menor $0,75 \mathrm{~m}$.

A identificação das amostras foi precedida da letra "T", de Tailing, seguida de uma numeração que obedeceu a ordem cronológica de sua coleta. As amostras foram coletadas da calha do trado, sendo primeiramente pesadas e, em seguida, divididas em duas alíquotas: a primeira alíquota era peneirada, bateada e analisada e a segunda alíquota peneirada, homogeneizada e quarteada, sendo uma fração enviada para análise por fluorescência de raio-X na LAKEFIELD ou CT-Gás (para obtenção de respostas analíticas mais rápidas) e a outra guardada como contra-amostra.

Em todas as fases de preparação da amostra eram tomados os pesos. Para cada furo foram tomados dados de profundidade (espessura), e realizadas análises químicas para $\mathrm{WO}_{3}$, cujos resultados estão listados na Tabela 4.

A opção pelo bateamento se deve ao fato das análises por fluorescência de raio-X serem na escala de percentagem cujo limite de detecção é considerado muito alto para trabalhos de Pesquisa Mineral e análise de Amostra Total. O pré-concentrado evidencia os minerais pesados e permite maior acurácia das análises. Em seguida calculava-se o teor "in situ", reportando-se ao peso inicial da amostra coletada quando da sondagem. A checagem foi feita com as contra-amostras que foram levadas para Gosla, Alemanha, laboratório da H C Strack. Lá elas foram submetidas ao peneiramento, em três faixas granulométricas, passíveis de reprodução na escala industrial e analisadas por fluorescência de raio-X. A preocupação residiu não somente na escala de produção, mas na realidade produtiva dos mineradores do Serido, conforme foi observado pelo engenheiro de minas, especialista em processamento mineral, Dr. Christian Cymorek, da empresa HC Starck, que acompanhou o processo de amostragem e observou as características de processamento de minério local.

Caso a quantidade de amostra fosse muito pequena, menor que $5 \mathrm{Kg}$ (cinco quilos), não se procedia àquela divisão de alíquota inicial. Nesse caso ou bateava-se toda a amostra de 
modo a produzir um concentrado de maior volume ou simplesmente adotava-se o procedimento descrito para a segunda alíquota.

No laboratório da STARCK utilizaram duas peneiras: a de $1 \mathrm{~mm}$ e a de 0,1 $\mathrm{mm}$. Foi analisado o passante e o retido em cada uma das mencionadas faixas obtendo-se o seguinte resultado geral, conforme listado na tabela 4.

A Média Ponderada ao volume de cada fração granulométrica presente nos Tailings é de $0,11 \% \mathrm{WO}_{3}$, coincidente com aquela encontrada pelos trabalhos de sondagem a trado manual. O maior volume corresponde ao material de Tailing com granulometria entre 1,0 e $0,1 \mathrm{~mm}$. Nessa faixa granulométrica o teor é de $0,10 \% \mathrm{WO}_{3}$. Ambas as faixas granulométricas acima de $1 \mathrm{~mm}$ e entre $1 \mathrm{~mm}$ e $0,1 \mathrm{~mm}$ possuem teor abaixo do teor de corte estimado que é da ordem de $0,12 \% \mathrm{WO}_{3}$.

TABELA 4 - RESULTADOS DA SONDAGEM A TRADO MANUAL EM TAILINGS

\begin{tabular}{|c|c|c|c|c|c|c|c|c|c|}
\hline AMOSTRA & UTM_E & UTM_N & PROF & $\mathbf{W O}_{3}$ & AMOSTRA & UTM_E & UTM_N & PROF & $\mathrm{WO}_{3}$ \\
\hline T 01 & 770997 & 9299158 & 1,65 & 0,12 & T 37 & 771076 & 9298838 & 2,80 & 0,16 \\
\hline T 02 & 770998 & 9299159 & 1,85 & 0,09 & T 38 & 771137 & 9299030 & 2,50 & 0,15 \\
\hline T 03 & 771067 & 9299132 & 1,45 & 0,11 & T 39 & 771050 & 9298904 & 2,75 & 0,16 \\
\hline T 04 & 771091 & 9299090 & 0,85 & 0,12 & T 40 & 771208 & 9299131 & 2,80 & 0,14 \\
\hline T 05 & 771180 & 9299336 & 0,75 & 0,16 & T 41 & 771261 & 9299136 & 3,00 & 0,11 \\
\hline T 06 & 771108 & 9299354 & 1,80 & 0,14 & T 42 & 771009 & 9299025 & 3,50 & 0,14 \\
\hline T 07 & 771086 & 9299308 & 2,00 & 0,14 & T 43 & 770981 & 9298904 & 3,10 & 0,08 \\
\hline T 08 & 771031 & 9299196 & 2,25 & 0,08 & T 44 & 770993 & 9298864 & 3,00 & 0,05 \\
\hline T 09 & 771196 & 9299068 & 2,10 & 0,10 & T 45 & 771053 & 9298756 & 3,00 & 0,12 \\
\hline T 10 & 771195 & 9299002 & 2,05 & 0,12 & T 46 & 771123 & 9298792 & 3,20 & 0,13 \\
\hline T 11 & 771093 & 9298920 & 2,30 & 0,12 & T 47 & 771184 & 9298763 & 3,30 & 0,13 \\
\hline T 12 & 770972 & 9298940 & 2,50 & 0,11 & T 48 & 771226 & 9298823 & 3,40 & 0,13 \\
\hline T 13 & 770964 & 9298992 & 3,12 & 0,10 & T 49 & 771276 & 9298960 & 3,40 & 0,14 \\
\hline T 14 & 770984 & 9299188 & 3,25 & 0,11 & T 50 & 770964 & 9299110 & 3,50 & 0,12 \\
\hline T 15 & 770970 & 9299134 & 2,55 & 0,05 & T 51 & 770962 & 9299065 & 4,00 & 0,11 \\
\hline T 16 & 770964 & 9299021 & 3,25 & 0,00 & T 52 & 770975 & 9299155 & 2,85 & 0,16 \\
\hline T 17 & 771020 & 9298810 & 2,80 & 0,16 & T 53 & 770988 & 9299193 & 3,10 & 0,17 \\
\hline T 18 & 771115 & 9298730 & 2,60 & 0,14 & T54 & 771006 & 9299227 & 3,00 & 0,12 \\
\hline T 19 & 771181 & 9298836 & 2,00 & 0,02 & T 55 & 771023 & 9299274 & 4,25 & 0,15 \\
\hline T 20 & 771257 & 9298892 & 2,75 & 0,14 & T 56 & 771097 & 9299365 & 3,80 & 0,14 \\
\hline T 21 & 771189 & 9298916 & 1,50 & 0,10 & T 57 & 771148 & 9299377 & 3,60 & 0,13 \\
\hline T 22 & 771284 & 9299021 & 1,65 & 0,08 & T 58 & 771193 & 9299292 & 3,20 & 0,13 \\
\hline T 23 & 771297 & 9299073 & 1,40 & 0,09 & T 59 & 771221 & 9299263 & 3,20 & 0,12 \\
\hline Т 24 & 771280 & 9299215 & 1,80 & 0,10 & T 60 & 771332 & 9299253 & 2,80 & 0,11 \\
\hline T 25 & 771316 & 9299292 & 1,90 & 0,11 & T 61 & 771159 & 9299251 & 2,50 & 0,09 \\
\hline T 26 & 771280 & 9299304 & 1,85 & 0,14 & T 62 & 771330 & 9299195 & 1,80 & 0,08 \\
\hline T 27 & 771218 & 9299204 & 1,85 & 0,12 & T 63 & 771315 & 9299134 & 0,75 & 0,10 \\
\hline T 28 & 771135 & 9299310 & 1,70 & 0,12 & T 64 & 771261 & 9299136 & 1,20 & 0,13 \\
\hline Т 29 & 771053 & 9299316 & 1,65 & 0,13 & T 65 & 771142 & 9299100 & 1,30 & 0,14 \\
\hline T 30 & 771091 & 9299256 & 2,60 & 0,14 & T 66 & 771149 & 9299174 & 1,20 & 0,12 \\
\hline T 31 & 771090 & 9299206 & 3,15 & 0,12 & T 67 & 771009 & 9298973 & 4,10 & 0,11 \\
\hline T 32 & 771013 & 9299087 & 3,85 & 0,15 & T 68 & 770976 & 9299034 & 3,45 & 0,08 \\
\hline T 33 & 771064 & 9299051 & 3,60 & 0,10 & T 69 & 771012 & 9299061 & 2,95 & 0,13 \\
\hline
\end{tabular}




\begin{tabular}{|l|l|l|l|l|l|l|l|l|l|}
\hline T 34 & 771128 & 9298960 & 3,50 & 0,11 & T 70 & 770988 & 9299094 & 3,00 & 0,12 \\
\hline T 35 & 771064 & 9298974 & 3,00 & 0,15 & T 71 & 771012 & 9299123 & 3,25 & 0,14 \\
\hline T 36 & 771124 & 9298874 & 2,70 & 0,14 & T 72 & 771009 & 9299193 & 2,00 & 0,12 \\
\hline
\end{tabular}

\begin{tabular}{|l|c|c|c|}
\hline \multicolumn{1}{|c|}{ LOCAL } & ÁREA (m²) & PROF. MÉDIA (m) & TEOR MÉDIO (\%) \\
\hline TAILING & 186.700 & 3,14 & 0,11 \\
\hline
\end{tabular}

A porção mais rica é aquela de fração granulométrica abaixo de $0,1 \mathrm{~mm}$ a qual, entretanto, corresponde apenas a 10\% do volume total de Tailings, conforme ilustrado na tabela 5 a seguir.

TABELA 5: RESULTADOS GERAIS DA AMOSTRAGEM EM Tailing

\begin{tabular}{|c|c|c|c|c|}
\hline & $+\mathbf{1 m m}$ & $\mathbf{1 . 0}-\mathbf{0 . 1} \mathbf{~ m m}$ & $\mathbf{- 0 . 1} \mathbf{~ m m}$ & MÉDIA PONDERADA \\
\hline Volume (\%) & 16 & 74 & 10 & - \\
\hline Teor de $\mathrm{WO}_{3}(\%)$ & 0,08 & 0,10 & 0,22 & 0,11 \\
\hline
\end{tabular}

Foi confeccionado um Mapa de Isoteor a partir da gridagem do MapInfo versão 7.5 e traçado o limite entre o material abaixo do teor de corte (vide tracejado preto na Figura 8). Outro limite foi desenhado visando separar o material passível de blendagem (traço branco na figura 8), ou seja, separando o material com teor igual ou superior ao Teor Limite. 


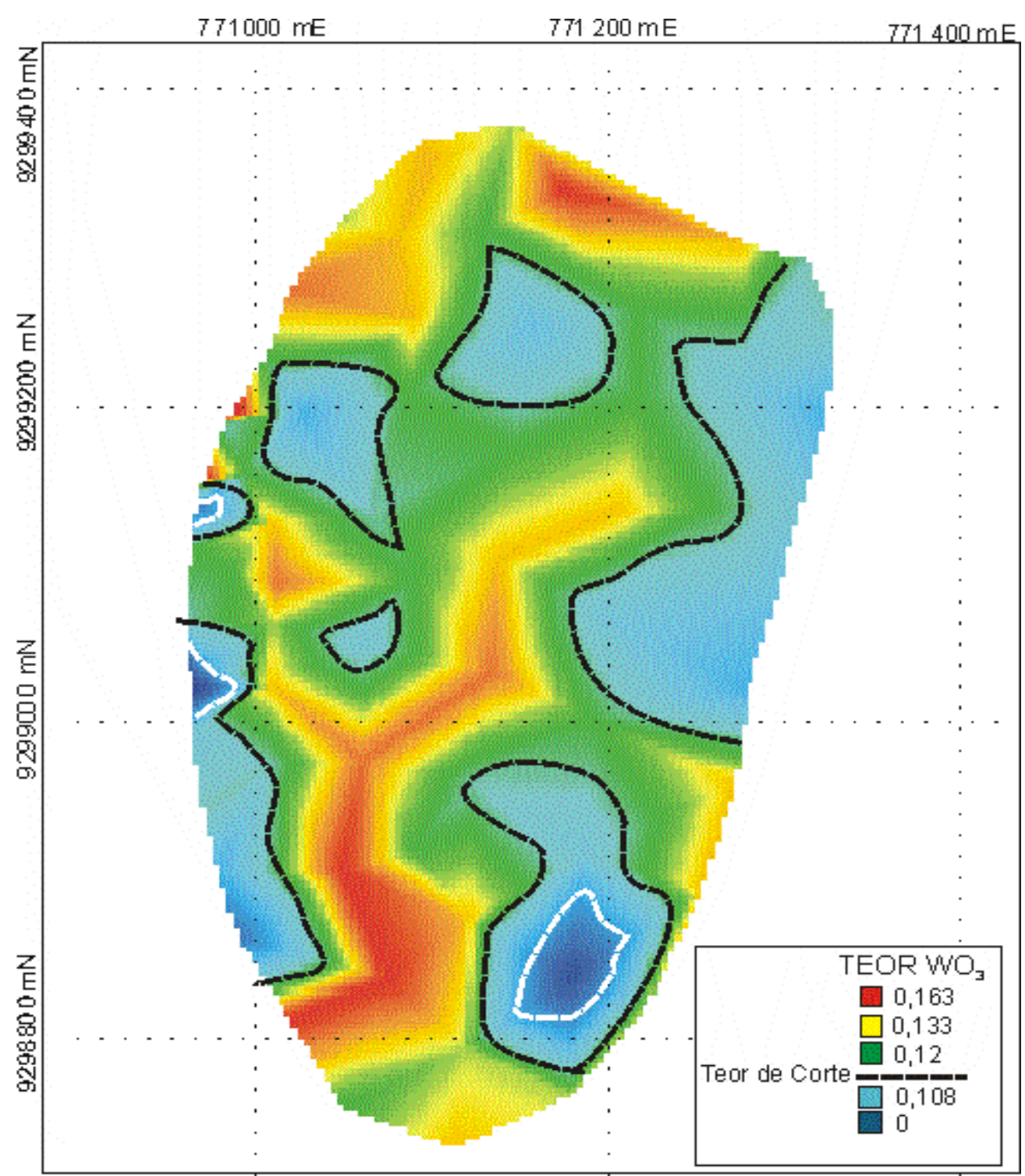

Figura 8: Mapa de Isoteor de $\mathrm{WO}_{3}$ com limites de teor de Corte (tracejado preto) e Teor Limite (tracejado branco), os dois últimos com respeito à estimativa de custos e preço de mercado relativo ao ano de 2007.

Esses mapas visam subsidiar os possíveis trabalhos de lavra de Tailings de maneira racional e produtiva. Importante observar que quase todo o Tailing possui teor aproveitável segundo a realidade econômica mineral do ano de 2007. Quando o teor não pode ser aproveitado diretamente, o aproveitamento pode se dá por processo de blendagem, uma vez que somente uma pequena parte do material encontra-se abaixo do Teor Limite correspondendo, no mapa da figura 8, a faixa azul escura que está delimitada por tracejado branco. Este Teor Limite é de $0,108 \% \mathrm{WO}_{3}$, podendo ser blendado, em partes iguais, com teor de $0,133 \%$ (faixa amarela na figura 8) uma vez que o resultado desta mistura (blendagem), nessas proporções, resulta em teor igual ao Teor de Corte $(0,12 \%)$.

Aqui se tomou o cuidado de calcular separadamente as Reservas Totais das Reservas Lavráveis, considerando essas últimas aquelas acima do Teor Limite, sem considerar as restrições de processamento mineral, não abordadas nesse trabalho. O programa MapInfo, versão 7.5, tornou mais simples este trabalho, uma vez que foram traçados polígonos irregulares sobre as faixas de interesse. Assim, foram digitalizadas áreas (com as poligonais 
irregulares - recurso do MapInfo 7.5) sobre aquelas faixas de teor abaixo do Teor Limite. O somatório dessas áreas foi subtraído da área total do Tailing para resultar na área de Reserva Lavrável, a qual mostrou ser cerca de 30\% menor que à da Reserva Total. Os teores e espessuras médias foram obtidos através de recurso do MapInfo que permite a seleção das amostras inseridas na área de Reserva Lavrável. No menu "Query” foi selecionada a opção "Calculate Statistics" para se obter os valores médios mencionados.

TABELA 6: RATEIO DAS RESERVAS MEDIDAS TOTAIS E LAVRÁVEIS

\begin{tabular}{|c|r|r|r|r|r|r|}
\hline RESERVAS & $\begin{array}{c}\text { PROF } \\
\text { MÉDIA }\end{array}$ & $\begin{array}{c}\text { TEOR } \\
\text { MÉDIO }\end{array}$ & $\begin{array}{c}\text { ÁREA } \\
\mathbf{( m}^{2} \mathbf{)}\end{array}$ & VOL $\left.\mathbf{( m}^{3}\right)$ & $\begin{array}{c}\text { TON } \\
\text { MINÉRIO }\end{array}$ & $\begin{array}{c}\text { TON. MIN. } \\
\text { MINÉRIO }\end{array}$ \\
\hline TOTAIS & 3,14 & 0,11 & 186.700 & 586238 & $1.055 .228,40$ & $1.160,75$ \\
\hline LAVRÁVEIS & 3,18 & 0,12 & 122.206 & 388613,87 & $699.504,97$ & 839,41 \\
\hline
\end{tabular}

O resultado da tabela 6 mostra que existe potencial econômico nos rejeitos, sendo aconselhável sua caracterização tecnológica para a determinação da rota adequada para o seu processamento. Ao preço de $\mathrm{R} \$ 20,00$ (Vinte Reais) o quilo de $\mathrm{WO}_{3}$ contido, tem-se que o valor econômico das jazidas de Tailing é de R\$ 16.788.119,00 (Dezesseis milhões, Setecentos e Oitenta e Oito mil, Cento e Dezenove Reais). Relembramos, todavia, que nessas projeções não foram consideradas as restrições da recuperação do processamento mineral, as quais podem alterar significativamente os teores de corte e limite e as reservas lavráveis.

\section{4 - Os Rejeitos de Run of Mine ou Bota - Fora}

Os "Bota-Foras" ou rejeitos de R.O.M. (Run Of Mine), formam blocos de rochas desmontadas das frentes de lavra, quando da produção de scheelita pela mina Barra Verde, onde uma parte do material lavrado seguia para a planta de processamento gravimétrico para produção de concentrados e de Tailing e a outra parte era descartada como rejeito. São principalmente blocos de gnaisses, mármores e calciossilicáticas portadora de scheelita de tamanhos diversos, desde diâmetros métricos até grãos sub-milimétricos e, secundariamente, de xistos, pegmatitos e granitóides. Estão localizados nas proximidades de onde funcionava o britador, ou seja, nas proximidades dos escombros da planta de tratamento. A maior parte do Bota-Fora está localizada em área de terceiros que não permitiram nosso acesso para realização desses trabalhos.

Esses "bota-foras" foram rejeitados por seu baixo teor de $\mathrm{WO}_{3}$ (geralmente abaixo do "cutoff" da época) ou devido a serem totalmente estéreis ou ainda devido as suas dimensões relativamente grandes em comparação à abertura do britador, sendo estocados a céu aberto para posterior fogacho que jamais foi realizado. Finalmente, o descarte desses "bota-foras" se deveu ainda a necessidade que as minas tinham, naquela época, de otimizar a escala de produção impedindo um controle desses descartes mais apurado, o quê possibilitou que materiais ricos em scheelita estivessem contidos nesses "bota-foras”. 


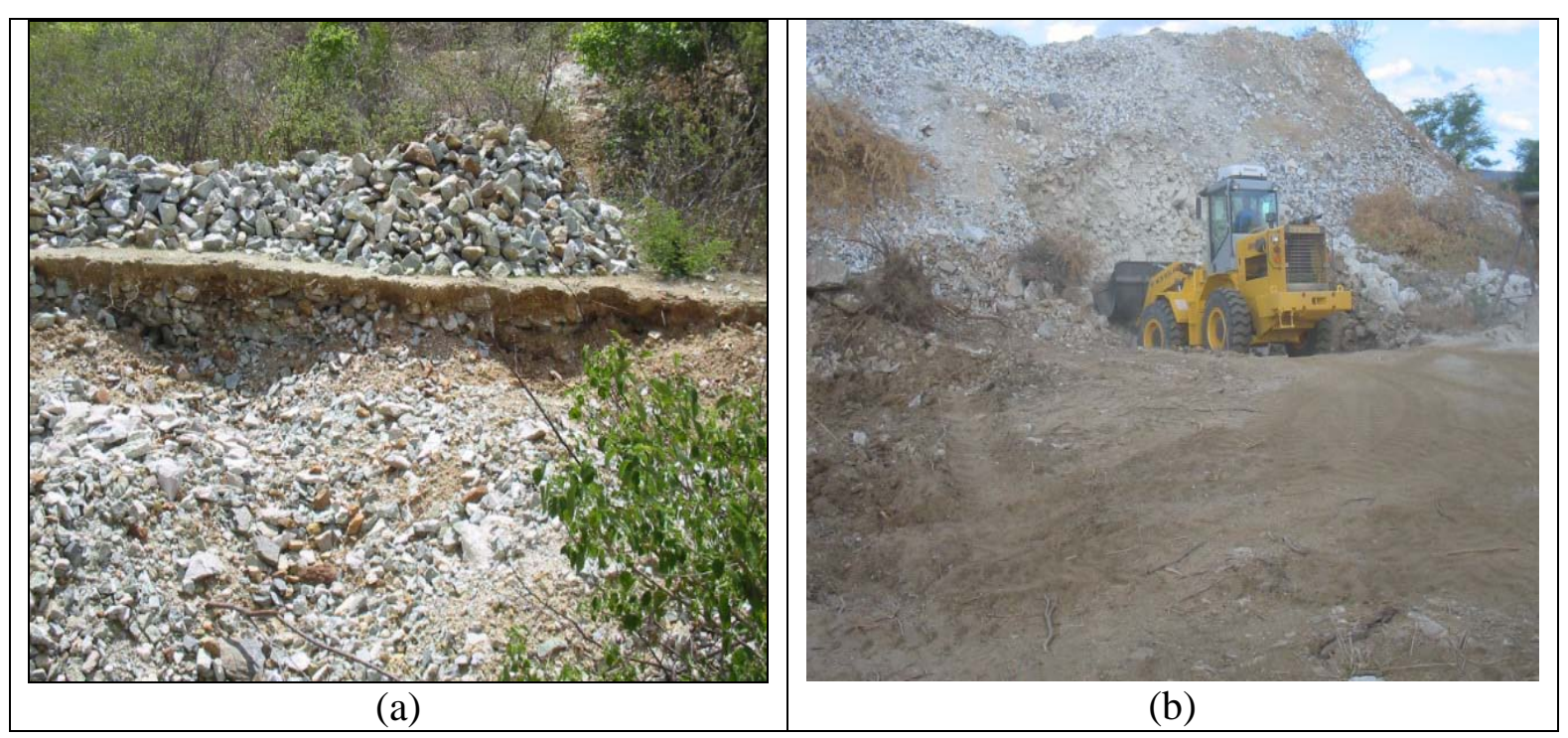

Figura 9: (a)Foto do “Bota-Fora” unidade estratigráfica correlata aos sedimentos antropogênicos mapeados na área da Mina Barra Verde e (b) operação de desmonte mecânico do Bota-fora.

Os procedimentos de campo para o mapeamento foram semelhantes àqueles utilizados para os Tailings. As coordenadas obtidas com GPS compuseram um banco de dados no Microsoft ACCESS e foram, em seguida, plotadas no MAPINFO 7.5.

Devido às características de alta heterogeneidade de tamanho e composição dos blocos, a realização de uma amostragem representativa torna-se bastante complicada. Decidiu-se, então, utilizar os dados da lavra, propiciada por trabalhos semi mecanizados realizados por duas equipes de pequenos empreendedores, entre os quais José Vilanir co-autor deste trabalho, e extrapolar os valores de teor para toda a área de incidência do "Bota-Fora". A espessura média utilizada foi àquela medida em sucessivas frentes de lavra expostas por desmonte manual e mecânico.

O método de lavra utilizado por essas duas equipes era bastante simples: primeiramente uma retro-escavadeira retirava todo o material a ser beneficiado e jogava-o em uma peneira de 3,5 x 3,5 m e malha de 1/4', (um quarto de polegada). Como tal peneira foi instalada com inclinação de aproximadamente $45^{\circ}$, o material passante tinha dimensões aproximadas de no máximo 1/8', (um oitavo de polegada).

O passante seguia para um moinho e, em seguida, para um jig de produção de préconcentrado, cuja intenção era de regulá-lo para concentrar os minerais de densidade igual e superior a da granada.

O retido era selecionado por catação por pessoal treinado para separar a calciossilicática das demais rochas presentes no "Bota-Fora". Em seguida as operações de britagem, de moagem, de peneiramento e jigagem semelhante àquela descrita para o material passante.

O pré-concentrado seguia para a planta de limpeza foi processado em mesa vibratória (mesa de desbaste e de limpeza final). Dependendo do resultado do concentrado da mesa esse material poderia ser ainda flotado, ustulado e eletroimado, para obtenção do concentrado em 
padrões comerciais locais (em torno de $70 \% \mathrm{WO}_{3}$ ). Sabendo a quantidade de "Bota-Fora" desmontado durante a semana e a produção semanal de concentrados, se obteve o teor recuperável do material "in situ”, ou seja, o teor de $\mathrm{WO}_{3}$ aproveitável industrialmente, inferindo esse teor para o restante do rejeito de run-of-mine.

Os dados históricos relativos ao acompanhamento da produção durante 3 meses forneceram um teor médio de $0,14 \% \mathrm{WO}_{3}$ e espessura média de $1,35 \mathrm{~m}$. Como resultado da cata, os blocos de calciossilicáticas chegam a $1 \% \mathrm{WO}_{3}$. Assim, considerando-se uma densidade média ponderada entre a de areia $(1,8)$ e rocha/"skarn” $(3,0)$, obteve-se $2,2 \mathrm{ton} / \mathrm{m}^{3}$. Os resultados estão apresentados sumariamente na Tabela 7.

TABELA 7: RATEIO DAS RESERVAS INFERIDAS DE “BOTA-FORA”

\begin{tabular}{|c|r|r|r|r|r|r|}
\hline $\begin{array}{c}\text { RESERVAS } \\
\text { DE }\end{array}$ & $\begin{array}{c}\text { PROF } \\
\text { MÉDIA }\end{array}$ & $\begin{array}{c}\text { TEOR } \\
\text { MÉDIO }\end{array}$ & $\begin{array}{c}\text { ÁREA } \\
\left(\mathbf{m}^{2}\right)\end{array}$ & $\begin{array}{c}\text { VOL } \\
\left(\mathbf{m}^{3}\right)\end{array}$ & $\begin{array}{c}\text { TON } \\
\text { MINÉRIO }\end{array}$ & $\begin{array}{c}\text { TON. MIN. } \\
\text { MINÉRIO }\end{array}$ \\
\hline “BOTA-FORA" & 1,35 & 0,14 & 5.328 & 7192,8 & 15824,16 & 22,153824 \\
\hline
\end{tabular}

Trata-se de uma pequena reserva de 22 toneladas de $\mathrm{WO}_{3}$ contido. Poder-se-ia chamá-la de reserva operacional (ver discussão adiante), uma vez que os dados foram obtidos do processo produtivo de tratamento.

\section{DISCUSSÕES, CONCLUSÕES E RECOMENDAÇÕES}

Os Depósitos Minerais Primários de scheelita são classificados, segundo a classificação dos Depósitos Minerais quanto a sua Regularidade estatística (adaptado de Kreiter in Maranhão, 1982 - vide Tabela 8), como Irregulares a Muito Irregulares, respectivamente $40 \%<\mathrm{V}<$ $100 \%$ a $100 \%<\mathrm{V}<150 \%$, com valores de Coeficiente de Variação (V) comumente na faixa de transição entre essas classes.

A mina Cafuca alternou períodos de lavra garimpeira e industrial ao longo de sua história produtiva (Nesi et. al. 1981) justificando assim maior Coeficiente de Variação que aquele observado na mina Barra Verde, cujo histórico foi preponderantemente de produção industrial.

\section{TABELA 8: CLASSIFICAÇÃO E ESPAÇAMENTO DA MALHA DE SONDAGEM DE ACORDO COM A REGULARIDADE E TIPO DE RESERVA}

\begin{tabular}{|c|c|c|c|c|}
\hline RESERVA & $\begin{array}{c}\mathbf{1}^{\mathbf{0}} \text { GRUPO } \\
5 \%<\mathrm{V}<40 \% \\
1^{\circ} \mathrm{Grupo}\end{array}$ & $\begin{array}{c}2^{\mathbf{O}} \text { GRUPO } \\
40 \%<\mathrm{V}<100 \% \\
2^{\circ} \text { Grupo }\end{array}$ & $\begin{array}{c}\mathbf{3}^{\mathbf{0}} \text { GRUPO } \\
100 \%<\mathrm{V}<150 \% \\
3^{\circ} \text { Grupo }\end{array}$ & $\begin{array}{c}\mathbf{4}^{\mathbf{0}} \text { GRUPO } \\
\text { V>150\% } \\
4^{\circ} \text { Grupo }\end{array}$ \\
\hline MEDIDA & 150 a $200 \mathrm{~m}$ & 25 a $100 \mathrm{~m}$ & $10 \times 10$ ou $20 \times 20$ & Somente com \\
\hline INDICADA & 200 a $400 \mathrm{~m}$ & 50 a $150 \mathrm{~m}$ & 50 a $70 \mathrm{~m}$ & Trabalhos \\
\hline INFERIDA & extrapolação & extrapolação & 90 a $150 \mathrm{~m}$ & mineiros \\
\hline INICIAL & $1000 \times 500$ & 200 a 300 & - & - \\
\hline
\end{tabular}




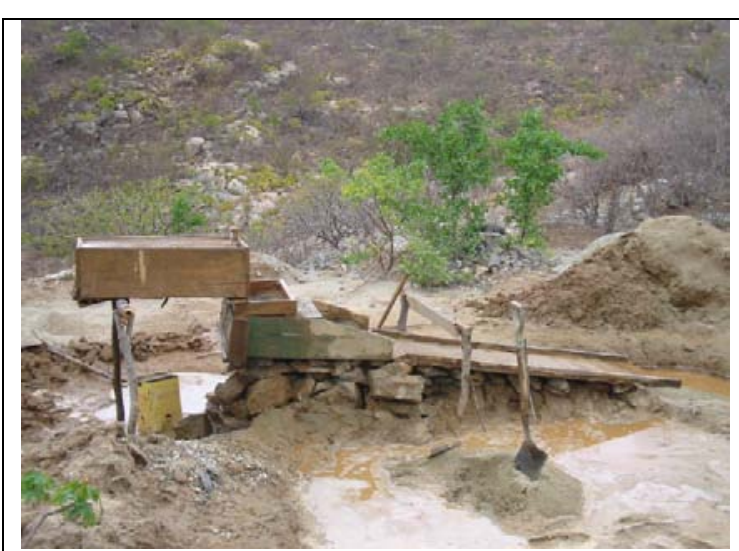

(a)

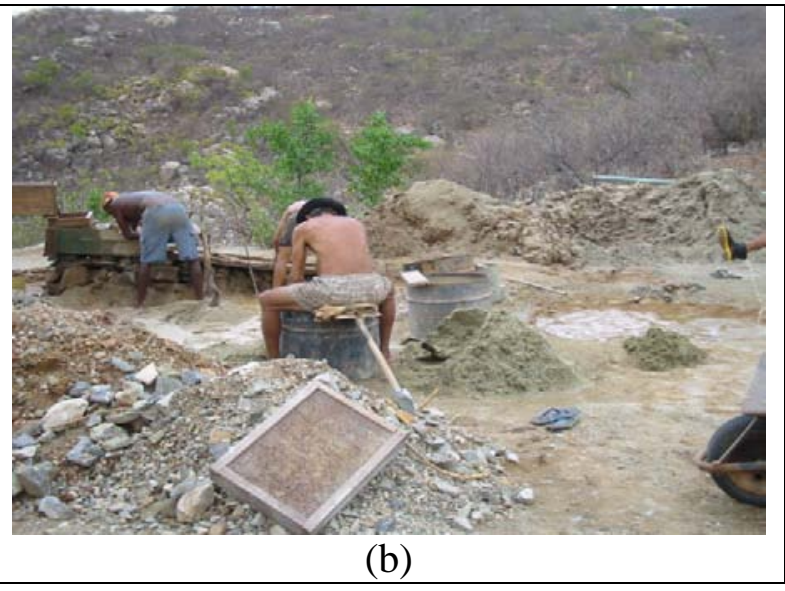

(b)

Figura 10: Flagrante de atividade de garimpagem na mina Cafuca em abril de 2006: (a) Caixa e (b) Concentração Manual com Batéia.

Contudo, tanto os resultados de Cafuca como de Barra Verde situam esse Depósito Antropogênico no primeiro grupo, ou seja, aqueles cujo Coeficiente de Variação estão na faixa entre 5\% e 40\% também denominados Depósitos Regulares, confirmando a tendência à homogeneização de teores no ambiente antropogênico à semelhança do que ocorre com a distribuição de teor no ambiente secundário (ver tabela 9).

\section{TABELA 9: MÉDIA, DESVIO PADRÃO E COEFICIENTE DE VARIAÇÃO DOS TAILINGS DAS MINAS CAFUCA E BARRA VERDE}

\begin{tabular}{|l|c|c|c|c|}
\hline \multirow{2}{*}{ Parâmetros Estatísticos } & \multicolumn{3}{|c|}{ MINA CAFUCA } & MINA BARRA \\
& $\begin{array}{l}\text { Por Fração Granulométrica } \\
>\mathbf{1 ~ m m}\end{array}$ & 1 mm - 0,1 mm & VERDE \\
\hline Média Aritmética & 0,22 & 0,38 & 1,04 & 0,117917 \\
\hline Desvio Padrão & 0,08 & 0,12 & 0,34 & 0,030945 \\
\hline Coef. Variação Aritimético & $36,28 \%$ & $32,53 \%$ & $32,79 \%$ & $26,2428 \%$ \\
\hline
\end{tabular}

A despeito das facilidades dos trabalhos da Prospecção e Pesquisa Mineral, as restrições de tecnologia de processamento mineral põem em cheque todos os ensaios que se pretenda fazer quanto à viabilidade econômica de uma operação industrial nos Tailings. Já nos BotaFora a situação se inverte, pois as rotas usuais de processamento minerais, usualmente utilizadas pelos mineradores (mineradoras e garimpeiros), parecem dar resultados satisfatórios.

Com respeito aos Tailings e as restrições do processamento mineral para determinação de Reservas Lavráveis, recorremos ao Código JORC (o 'JORC Code’ 1989 ou, simplesmente, as NORMAS JORC), que determina os requisitos fundamentais, diretrizes e recomendações para o preparo de Relatórios Públicos com resultados de exploração mineral e estimativas de Recursos Minerais e Reservas de Minério na Australásia (Australasian Code for Reporting of Mineral Resources and Ore Reserves - The JORC Code). Os principais requisitos para uso e aplicação das NORMAS são transparência, materialidade e competência. 'Transparência' exige que o leitor do Relatório receba informação suficiente, clara e inequívoca, para compreender e não ser induzido a erros. 'Materialidade' requer que o 
Relatório Público contenha todas as informações relevantes que os investidores e seus assessores profissionais normalmente necessitam, e que esperam encontrar no relatório, permitindo-lhes um julgamento racional e balanceado sobre a mineralização relatada. 'Competência' requer que o Relatório Público seja baseado em trabalho de responsabilidade de pessoa devidamente qualificada e experiente, sujeita a um código de ética profissional que possa ser devidamente monitorado e fiscalizado.

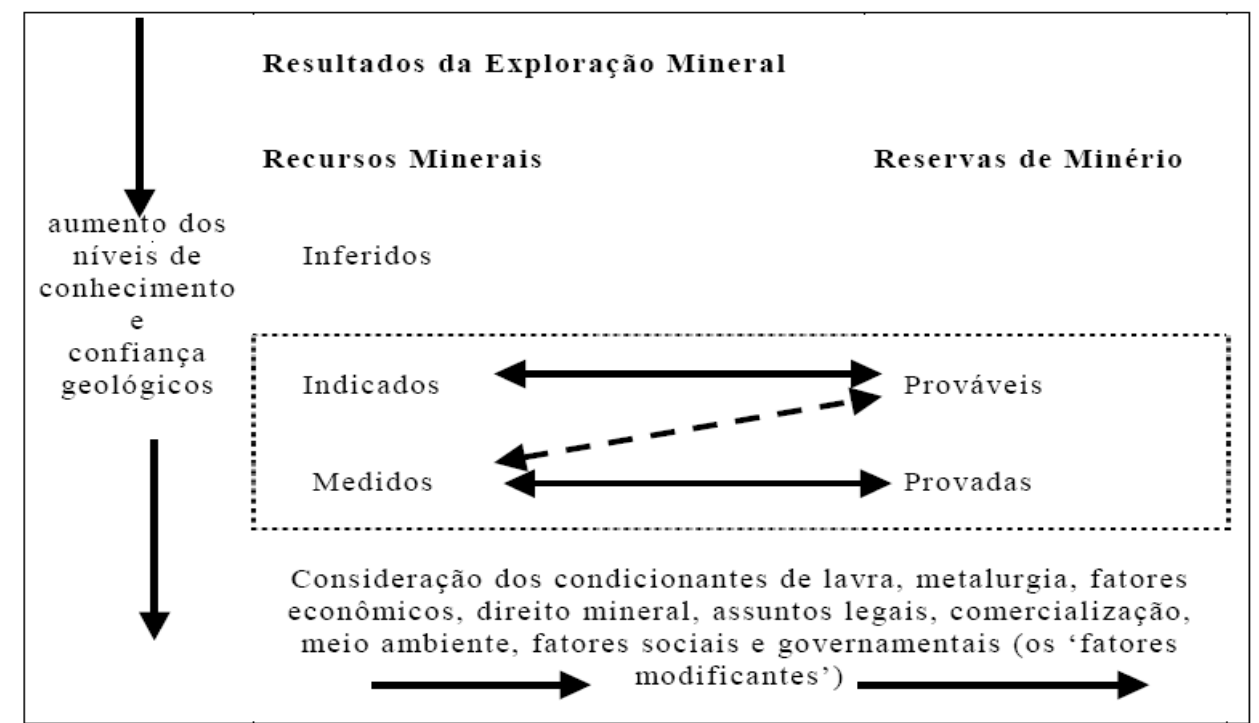

Figura 11: Relações entre Resultados de Exploração Mineral, Recursos Minerais e Reservas de Minério. Copiado do JORC Code.

Tentando classificar as quantidades de $\mathrm{WO}_{3}$ cubadas de Tailings das minas Barra Verde e Cafuca encontramos, na definição dada pelas Normas JORC (ver também a figura 11), que 'Recurso Mineral' é uma concentração ou ocorrência de material de interesse econômico na crosta terrestre, ocorrendo de uma forma e quantidade tais que justificam razoáveis perspectivas para uma eventual extração econômica. A localização, quantidade, teor, características geológicas e continuidade de um Recurso Mineral é conhecido, estimado ou interpretado a partir de evidências e conhecimentos geológicos específicos. Pela ordem de confiança geológica crescente, os Recursos Minerais são subdivididos nas categorias Inferidas, Indicadas e Medidas. As Normas JORC definem ainda que uma 'Reserva de Minério' é a parte economicamente lavrável de um Recurso Mineral Medido ou Indicado, sendo classificada em Provadas e Prováveis, respectivamente. Inclui materiais diluídos no minério e descontos para perdas que poderão ocorrer quando o minério for lavrado. Reservas de Minério são aquelas partes dos Recursos Minerais que, após a aplicação de todos os fatores de lavra, resultam em uma estimativa de tonelagem e teor que, na opinião da Pessoa ou Pessoas Competentes fazendo à estimativa, pode ser a base de um projeto viável, pois leva em consideração todos os fatores relevantes de ordem metalúrgica, econômica, comercialização, direito mineral, assuntos legais, meio ambiente, e fatores sociais e governamentais. As Reservas de Minério incluem material diluído ao minério, que será lavrado em conjunto com as Reservas de Minério e enviado à planta de tratamento ou equivalente.

Assim, enquanto não se viabilizar rotas econômicas de tratamento de minério, os Tailings de scheelita do Seridó só poderão ser classificados como Recursos Minerais pelas normas JORC, cuja viabilidade de uma lavra industrial é, ainda, duvidosa. 
Finalmente, ressaltamos o estado contemplativo onde, de um lado, uma riqueza mineral disponível e quantificada e, do outro lado, uma região com poucas oportunidades de geração de renda e emprego. A falta de uma maior empatia entre as instituições de pesquisa, indústria de mineração e sociedade em geral visando buscar alternativas viáveis, parece ser o maior entrave para a resolução destas restrições.

\section{REFERÊNCIAS BIBLIOGRÁFICAS}

1. CARVALHO, E. B.; LIMA, R. F. S.; PETTA, R. A.; PAULO, J. B. A.; SOUZA, L. C. Caracterização de rejeitos provenientes da usina de beneficiamento do minério da Mina Brejuí/RN. In: XIX Encontro Nacional de Tratamento de Minérios e Metalurgia Extrativa, 2002, Recife-PE. Anais do XIX Encontro Nacional de Tratamento de Minérios e Metalurgia Extrativa. Recife-PE : Carlos Adolpho M. Baltar, 2002. v. I. p. 75-81

2. CAVALCANTI Nt, M. T. O. , JARDIM DE SÁ, M. E. F.; SALIM, J. Geologia da Faixa da Mina Brejuí, Currais Novos/RN: Reavaliação de Dados. In: XXXV Congresso Brasileiro de Geologia, v. 7. p. 2772-2774, 1988.

3. JORC Code. Australasian Code for Reporting of Mineral Resources and Ore Reserves (The JORC Code). Joint Ore Reserves Committee (JORC) - The JORC Code. 1989.

4. MARANHÃO, Ricardo Jorge Lobo. Introdução a Pesquisa Mineral. Fortaleza: Banco do Nordeste do Brasil, 1982. 680 p.

5. LEITE, J. Y. P; ARAUJO, F. S. D; SANTOS, E. P. Análise das Plantas de Concentração de Scheelita do Estado do RN. II Jornada Nacional da Produção Científica em Educação Profissional e Tecnológica, São Luiz/MA, 2007.

6. NESI, J. de R.; SOUZA, G.M.C. de; TINOCO SOBRINHO, J. Considerações sobre a importância dos jazimentos scheelitíferos que compõem a faixa calcário-escarnítica de Riachão-Bodó-Cafuca-Santana do Matos/RN. In: SIMPÓSIO DE GEOLOGIA DO NORDESTE, 10. Recife, 1981. Atas. Recife, SBG, 1981. 513p. il. (Boletim do Núcleo Nordeste da SBG, 8). p.204-212.

7. PFEIFER H R, Environmental risks related to natural and mineral ore deposits of the Central and Western Alps. Schweiz. Mineral.Petrogr. Mitt. 79, pp. 339-40., 1999.

8. SEDEC. Passivo Ambiental no Setor Mineral do RN (http://www.sedec.rn.gov.br/Cd\%20codem/Cap\%C3\%ADtulos\%20em\%20PDF\%20Revi sados/Cap\%C3\%ADtulo\%206\%20Passivo\%20Ambiental\%20no\%20Setor\%20Mineral.p df)

9. SILVA Jr, E. F. da, SAMPAIO, J. A. e GUZZO, P. L. Estudo do Fracionamento de Estéreis e Rejeito da Lavra de Scheelita na Província Borborema (RN) por Separação Magnética e Líquidos Densos. XVI Jornada de Iniciação Científica, CETEM, 2008. 